\title{
EVALUANDO EL PROCESAMIENTO VEGETAL Y LA ELABORACIÓN DE BEBIDAS FERMENTADAS EN UN CONTEXTO EL VERGEL DE ISLA MOCHA (1000-1300 d.C.)
}

\author{
EVALUATING VEGETABLE PROCESSING AND THE ELABORATION OF \\ FERMENTED BEVERAGES IN AN EL VERGEL CONTEXT IN MOCHA ISLAND \\ (AD 1000-1300)
}

Carolina Godoy-Aguirre ${ }^{1}$

\begin{abstract}
La evidencia carpológica en contextos del Complejo El Vergel en Isla Mocha ha posibilitado la inferencia de variados usos que estos grupos dieron a sus recursos vegetales. Entre estos destaca la hipótesis del empleo de Zea mays para la elaboración de bebidas fermentadas que se habrían insertado entre las prácticas de prestigio y liderazgo vinculadas a procesos de complejización social en El Vergel. Si bien la producción de estos brebajes se encuentra refrendado por el registro etnohistórico rechemapuche, se desconocen hasta ahora antecedentes arqueológicos que entreguen información contextual sobre estas prácticas en El Vergel. Este trabajo analiza granos de almidón arqueológicos recuperados de fragmentos cerámicos, comparando sus daños con el patrón descrito para el proceso de fermentación en la literatura especializada. Nuestros resultados muestran una producción de estos brebajes en Isla Mocha al menos entre los 1000 a 1300 d.C., utilizando para este fin especies cultivadas y silvestres: Aristotelia chilensis (maqui), Zea mays (maíz) y posiblemente Fragaria chiloensis (frutilla silvestre). Las categorías morfofuncionales cerámicas indican que el proceso completo de elaboración y servicio de estos brebajes se realizaría dentro del mismo sitio, estando la etapa de servicio posiblemente vinculada a la cerámica decorada, la cual estaba probablemente especificada para este fin.
\end{abstract}

Palabras claves: arqueobotánica, microrrestos vegetales, modalidades de procesamiento, bebidas fermentadas,

Complejo El Vergel.

Carpological evidence of El Vergel Complex contexts in Isla Mocha has made it possible to infer the various uses that these groups made of their vegetable resources. Among these, the hypothesis that Zea mays was used for the elaboration of fermented drinks-which would have been part of the prestige and leadership practices related to the increase in social complexity-stands out. Although the production of these beverages is noted in the Reche-Mapuche ethnohistorical record, archaeological evidence that provides contextual information about these practices at $\mathrm{El}$ Vergel is unknown. This work analyzes the archaeological starch grains recovered from ceramic sherds by comparing their damage with the pattern described for the fermentation process in the specialized literature. Our results show the production of these beverages in Mocha Island at least between A.D. 1000 and 1300, with both cultivated and wild species used for this purpose: Aristotelia chilensis (maqui), Zea mays (maize) and possibly Fragaria chiloensis (wild strawberry). The ceramic morphofunctional categories indicate that the complete process of preparing and serving these beverages would have taken place within the same site, with the serving stage possibly being linked to decorated pottery, which was likely specified for this purpose.

Key words: Archeobotany, plant micro-remains, processing modalities, fermented beverages, El Vergel Complex.

\section{El Vergel de Isla Mocha, sus Recursos Vegetales y su Relación con la Producción de Bebidas Fermentadas}

Isla Mocha se emplaza en las costas de la Provincia de Arauco aproximadamente a $34 \mathrm{~km}$ de Tirúa (VIII Región del Bíobío). Los sitios arqueológicos más ubicuos en esta isla son los pertenecientes al Complejo El Vergel (10001550 d.C.) (Campbell 2011). Estos grupos se caracterizaron por poseer una economía mixta, tanto apropiativa como productiva (Aldunate 2005; Sánchez et al. 2004). En el caso de los recursos vegetales este tipo de economía se traduce en un aprovechamiento de diversas especies, tanto silvestres como domesticadas (Roa et al. 2014; Rojas y Cardemil 1995; Sánchez et al. 2004; Silva 2010a, 2010b, 2014). Entre los recursos cultivados encontramos: Zea mays (maíz), Chenopodium quinoa (quínoa), Phaseolus vulgaris (poroto) y

$\overline{1}$ Pontificia Universidad Católica de Chile, Santiago, Chile. carolina.godoy.ag@gmail.com

Recibido: marzo 2017. Aceptado: diciembre 2017.

http://dx.doi.org/10.4067/S0717-73562018005000401. Publicado en línea: 14-marzo-2018. 
posiblemente Bromus mango (magu), mientras que entre las especies silvestres destacan: frutilla silvestre (Fragaria chiloensis), maqui (Aristotelia chilensis), frambuesa silvestre (Rubus geoides), peumo (Cryptocarya alba), ñocha (Cyperus sp.), quilo (Muehlenbeckia hastulata) y vatro (Typha angustifolia) (Roa 2011, 2016; Roa et al. 2014; Silva 2010a, 2010b, 2014).

Los estudios arqueobotánicos en Isla Mocha han logrado proponer algunos tipos de usos para estos recursos vegetales: materia prima, combustible, medicina, alimento y usos sociopolíticos (Campbell 2011; Roa et al. 2014; Silva 2014). En este estudio ponemos énfasis en los usos sociopolíticos hipotetizados para ciertas especies. Particularmente el maíz (Zea mays L.) se ha vinculado con una posible producción de chicha para su uso en momentos de agregación social dentro de Isla Mocha (Campbell 2011; Roa et al. 2014). Esta hipótesis cobra gran relevancia teniendo en cuenta que el control político en estos grupos se basaría en la posesión y circulación de bienes de prestigio, no así en un control coercitivo o económico de los recursos (Campbell 2011; Dillehay 2007). En este sentido, las bebidas fermentadas son entendidas como un tipo de cultura material (Dietler 2001), ya que los recursos vegetales deben ser transformados y reproducidos de acuerdo a las instancias de socialización para las cuales son preparados (Pazzarelli 2014). Existen múltiples ejemplos de cómo este tipo de cultura material es un elemento que se enviste de importancia política, económica y religiosa en diferentes regiones del mundo (Arthur 2003; Bray 2009; Dietler 2001, 2006; Dietler y Hayden 2001; Dietler y Herbich 2006; Hayashida 2008; Ikehara et al. 2013; Jennings 2004; Jennings y Bowser 2009; Juan-Tresserras 2000; Logan et al. 2012; Pazzarelli 2014; Samuel 1996; Vinton 2009). Para nuestro caso de estudio, sabemos que en algunas sociedades donde no existen instituciones políticas formales o centralizadas se suelen establecer jerarquías mediante hospitalidad comensal y manipulación de las libaciones de alcohol (Arthur 2003; Dielter 2001). La temática de las bebidas fermentadas posee además importantes antecedentes etnohistóricos en Araucanía: particularmente las "juntas" de los grupos rechemapuche habrían sido instancias privilegiadas para representar la riqueza de un cacique y su unidad social, exhibiendo la disposición de recursos entre los cuales se destacaban las bebidas fermentadas (Adán 2014; Boccara 2007; Pardo y Pizarro 2005; Núñez de Pineda 1863; Quiroga 1979 [1692]). Pese a lo anterior, se reconoce que las actividades de preparación de estas "juntas" - entre ellas la elaboración de bebidas fermentadas-corresponden a un componente doméstico y cotidiano hasta ahora escasamente explorado (Adán 2014).

Otros antecedentes arqueológicos de esta problemática en Araucanía pueden hallarse en las zonas de Purén y Lumaco, específicamente en dos contextos ceremoniales: LU-69 y PU165 (Dillehay y Saavedra 2010; Iriarte 2014). En ambos sitios se identificaron silicofitolitos de Zea mays L., sugiriendo que el maíz fue probablemente consumido en forma de alimentos y/o bebidas fermentadas que habrían cumplido funciones importantes en el espacio ceremonial (Iriarte 2014). Por su parte, los estudios que plantean posible utilización del maíz para elaboración de estos brebajes en Isla Mocha se basan en la recuperación de carporrestos (Roa 2011, 2013; Roa et al. 2014; Silva 2010b), además de información etnohistórica correspondiente a la expedición holandesa de Van Noort, quien visitó este territorio en 1600 siendo espectador de una ceremonia donde se repartía chicha de maíz (IJzerman 1926 [1602]). Al respecto Silva (2014) repara en ciertas limitaciones del registro carpológico: la misma elaboración de las bebidas fermentadas (trituramiento y ausencia de carbonización de los frutos) conlleva la nula conservación de estos como carporrestos. Teniendo en cuenta la preparación de estas bebidas, planteamos que los microrrestos contenidos en la cerámica serían un medio privilegiado para su estudio, ya que su elaboración estaría íntimamente ligada al material cerámico en tiempos reche-mapuche (Alvarado 1997a, 1997b; Coña 2010 [1930]; Musaubach y Berón 2012; Núñez de Pineda 1863; Pardo y Pizarro 2005).

\section{El Sitio P5-1}

El sitio P5-1 se ubica en el sector nororiental de Isla Mocha y posee aproximadamente 15 ha (Figura 1). Corresponde a un sitio doméstico donde se habría llevado a cabo la elaboración y consumo de grandes cantidades de alimentos hasta ahora indeterminados, algunos de los cuales pudieron ser almacenados para épocas de festividades de acuerdo al importante tamaño de la cerámica recuperada en el contexto (Albán et al. 2013). Este sitio se ha interpretado además como un contexto socialmente "privilegiado" debido a varias características que lo hacen único dentro de Isla Mocha: es uno de los sitios con mayor extensión en la isla, y posee varias peculiaridades en cuanto a los materiales presentes, tales como una alta proporción de materias primas líticas foráneas y de buena calidad, la presencia de piezas metálicas exclusivas y la mayor diversidad de tipos de cerámica decorada 
dentro de la isla (Campbell 2013; Palma et al. 2015). Estas particularidades, además de su relativa cercanía a los kuels o monumentos públicos ubicados en el mismo sector nororiental de Isla Mocha, permitieron considerar este contexto como adecuado para evaluar la producción de bebidas fermentadas en El Vergel.

En este estudio se analizó material procedente del pozo de sondeo 06.01.01 (Figura 2). Este pozo se emplaza en el sector que presentó la mayor concentración de fragmentos cerámicos en el sitio (1.332 fragmentos, tanto decorados y sin decoración, algunos con huellas de uso). Sus fechas comprenden dos bloques temporales distinguibles: el primero alrededor del 1000 d.C. correspondiendo a las capas estratigráficas más profundas $(90-95 \mathrm{~cm}$ de profundidad), y el segundo de ellos alrededor del 1300 d.C., correspondiente a sus a capas intermedias (entre 35 y $75 \mathrm{~cm}$ de profundidad) (Tabla 1); no se pudieron obtener fechados absolutos para las capas superficiales (sobre los $35 \mathrm{~cm}$ de profundidad) (Campbell y Pfeiffer 2016).

\section{Los Microrrestos Vegetales y su Potencial para Inferir Modos de Procesamientos en el Pasado}

Los microrrestos vegetales corresponden a partículas microscópicas de origen vegetal: almidones, silicofitolitos, fitolitos de calcio o calcifitolitos, cristales de oxalato cálcico, granos de polen y esporas (Loy 1994; Mulholland y Rapp 1992). Algunos de estos elementos resultan diagnósticos de su origen anatómico y/o taxonómico (Babot 2007; Esau 1976; Loy 1994; Mulholland y Rapp 1992).

Por su parte, las modalidades de procesamiento corresponden a un enfoque arqueobotánico que busca comprender las transformaciones culturales sobre los recursos vegetales (Babot 2006). Para ello se recaba información etnográfica y moderna sobre técnicas culinarias, realizando posteriormente estudios actualísticos sobre los recursos vegetales. Cada modalidad de procesamiento genera patrones de daño sobre las propiedades físico químicas normales de los microrrestos vegetales, especialmente en el almidón (Babot 2003, 2006, 2007, 2009). Estos daños, asociados al contexto de las evidencias, permiten inferir las modalidades de procesamiento que sufrieron los microrrestos vegetales en el pasado (Babot 2003, 2006, 2009; Babot et al. 2012).

\section{Material y Método}

Las muestras proceden del raspado simple de fragmentos cerámicos, recuperados del pozo de sondeo 06.01.01 del sitio P5-1 en Isla Mocha (Tabla 2). Los fragmentos fueron revisados previo a su lavado, escogiéndose cuerpos y bases, para luego ser clasificados según categorías de espesor:

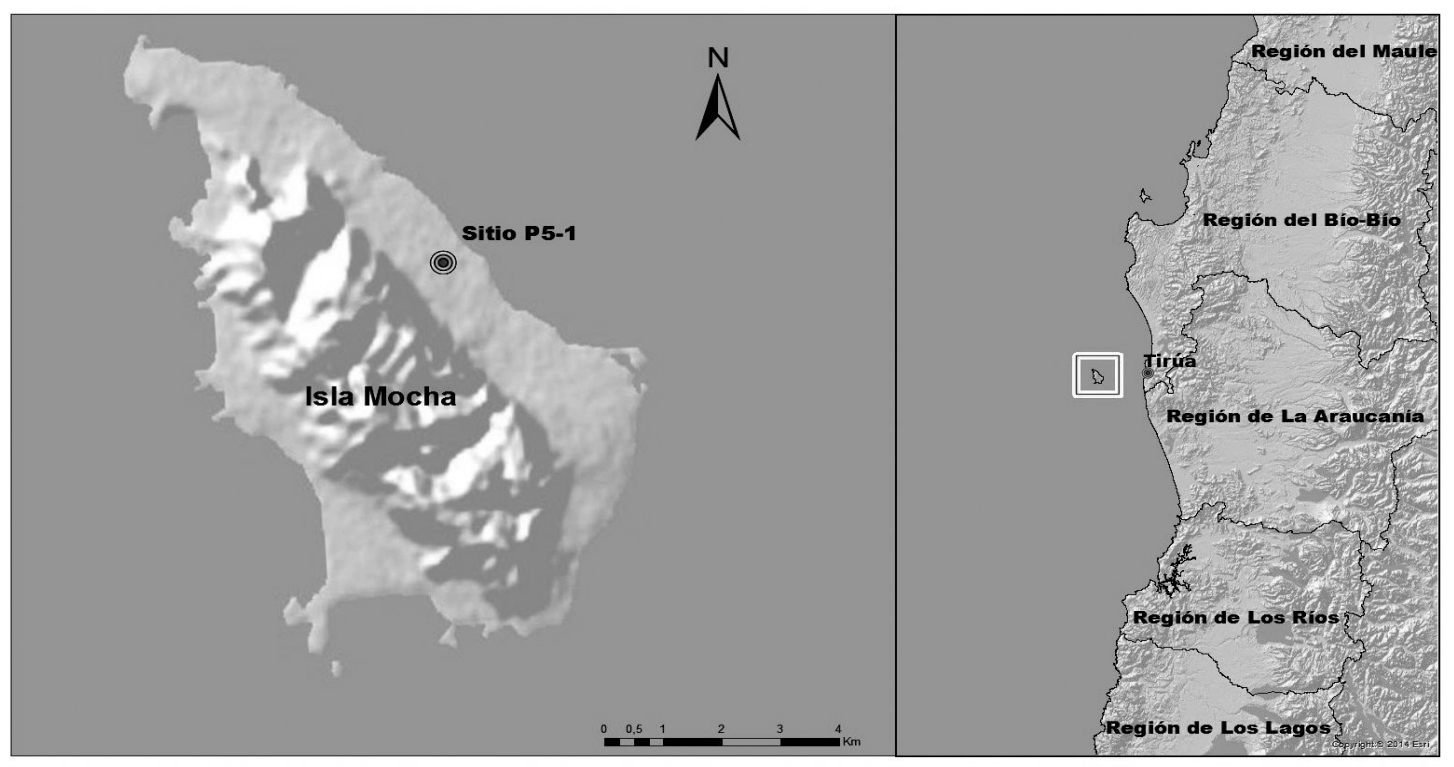

Figura 1. Localización del sitio P5-1 en el sector nororiental de Isla Mocha. Location of P5-1 site in the northeastern sector of Mocha Island. 


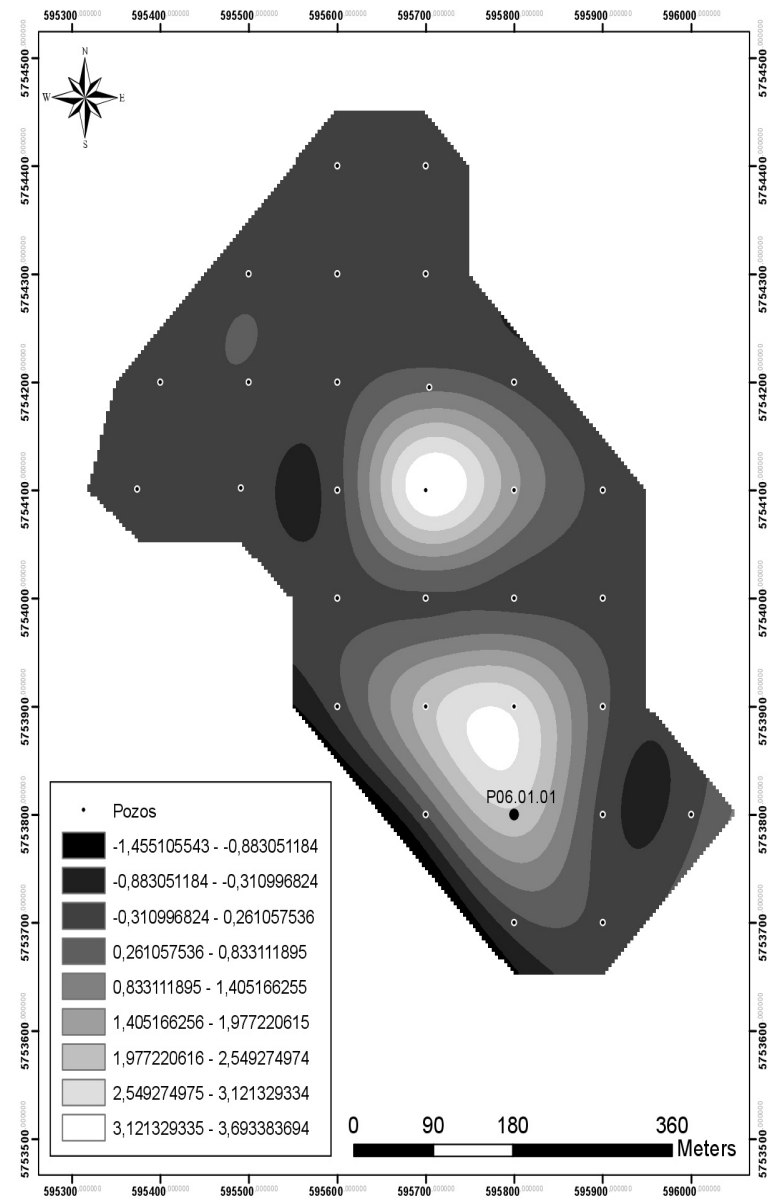

Figura 2. Pozos de sondeo del sitio P5-1 de acuerdo a la concentración de material cerámico. Test pits at P5-1 site according to the concentration of ceramic material.

Tabla 1. Fechados de radiocarbono obtenidos para el sitio P5-1, Isla Mocha. Radiocarbon dates obtained for P5-1 site, Mocha Island.

\begin{tabular}{|c|c|c|c|c|c|c|}
\hline $\begin{array}{l}\text { Profundidad } \\
\quad(\mathrm{cm})\end{array}$ & Capa & $\begin{array}{l}\text { Material } \\
\text { fechado }\end{array}$ & $\begin{array}{c}\text { Código } \\
\text { laboratorio }\end{array}$ & Fechado ${ }^{14} \mathrm{C}$ & $\begin{array}{c}\text { Rango } \\
\text { calibrado } \\
\text { d.C. (2 } \\
\text { sigmas) }\end{array}$ & $\delta^{13} \mathrm{C}$ \\
\hline $35-40$ & 2 & $\begin{array}{l}\text { Chenopodium } \\
\text { quinoa }\end{array}$ & UB 24523 & $816 \pm 27$ & $\begin{array}{l}1218- \\
1282\end{array}$ & $-27,9$ \\
\hline $35-40$ & 2 & Camelidae & UB 26213 & $751 \pm 35$ & $\begin{array}{l}1229- \\
1386\end{array}$ & --- \\
\hline $55-60$ & 3 & $\begin{array}{l}\text { Chenopodium } \\
\text { quinoa }\end{array}$ & UB 24524 & $718 \pm 22$ & $\begin{array}{l}1281- \\
1385\end{array}$ & $-28,6$ \\
\hline $70-75$ & 3 & Zea mays & UB 24525 & $796 \pm 25$ & $\begin{array}{l}1225- \\
1288\end{array}$ & $-9,0$ \\
\hline $90-95$ & 4 & Zea mays & UB 24526 & $992 \pm 30$ & $\begin{array}{l}1025- \\
1157\end{array}$ & $-9,7$ \\
\hline
\end{tabular}

muy delgado (menos de 4,24 mm), delgado (4,25 a 7,24 $\mathrm{mm}$ ), mediano $(7,25$ a $10,24 \mathrm{~mm})$, grueso $(10,25$ a $13,24 \mathrm{~mm})$ y muy grueso (sobre 13,25 $\mathrm{mm}$ ) (Campbell 2011). Luego, se seleccionó aleatoriamente el 10\% de cada categoría de espesor en cada nivel. Los fragmentos fueron adscritos posteriormente a categorías morfofuncionales de acuerdo a su espesor y tratamiento de superficie: jarros, cuencos o escudillas, ollas o urnas (Palma 2013). Cada fragmento cerámico fue lavado con agua destilada y luego de su secado se realizó extracción directa de microrrestos mediante raspado en seco de la superficie interior del fragmento (Loy 1994; Loy y Fullagar 2006). Para cada raspado se utilizó un palillo plástico, el cual fue previamente lavado mediante alcohol y agua destilada y fue desechado luego de cada extracción. Adicionalmente, se obtuvo una muestra de control para análisis de los microrrestos depositados en el sedimento del sitio, considerando una muestra en cada una de las capas estratigráficas (de un total de 
cuatro capas). Todas las muestras tuvieron un peso estandarizado de $0,001 \mathrm{gr}$ y fueron montadas en portaobjetos mediante aceite de inmersión.

Cada muestra fue analizada en su totalidad mediante microscopio petrográfico con luz transmitida, polarizada y analizador de cuarzo, utilizando aumentos de 200x y 400x. La descripción de microrrestos siguió los estándares del Código Internacional para Nomenclatura de Fitolitos creado por ICPN Working Group (2005), mientras que la descripción de almidones se ajustó a los criterios referenciados en la literatura especializada (Babot 2007; Korstanje y Babot 2007) y la nomenclatura expuesta en The International Code for Starch Nomenclature (ICSN 2011). La cuantificación de evidencias se realizó utilizando índice de ubicuidad, calculando la frecuencia total de cada tipo de microrresto y dividiendo este valor por la suma total de fragmentos analizados (Popper 1988), mientras que la identificación taxonómica se obtuvo por comparación con colecciones de referencia (Albornoz 2014; Belmar 2017; Godoy-Aguirre 2014).

Los daños presentes en almidón se analizaron de acuerdo a las modificaciones físico químicas

Tabla 2. Número de muestras cerámicas según nivel y capa del pozo 06.01.01.

Number of ceramic samples according to level and layer of test pit 06.01.01.

\begin{tabular}{|c|c|c|c|c|}
\hline $\begin{array}{l}\text { Nivel } \\
(\mathrm{cm})\end{array}$ & Capa & $\begin{array}{l}\text { Total } \\
\text { fragmentos } \\
\text { cerámicos }\end{array}$ & $\begin{array}{l}\text { Fragmentos } \\
\text { cerámicos } \\
\text { muestreados }\end{array}$ & $\begin{array}{c}\% \text { Total } \\
\text { muestreado }\end{array}$ \\
\hline $0-10$ & & 17 & 4 & 23,5 \\
\hline $10-15$ & & 90 & 10 & 11,1 \\
\hline $15-20$ & 1 & 80 & 7 & 8,8 \\
\hline $20-25$ & & 103 & 11 & 10,7 \\
\hline $25-30$ & & 137 & 13 & 9,5 \\
\hline $30-35$ & & 96 & 9 & 9,4 \\
\hline $35-40$ & & 74 & 8 & 10,8 \\
\hline $40-45$ & 2 & 96 & 9 & 9,4 \\
\hline $45-50$ & & 72 & 9 & 12,5 \\
\hline $50-55$ & & 105 & 10 & 9,5 \\
\hline $55-60$ & & 106 & 10 & 9,4 \\
\hline $60-65$ & & 99 & 9 & 9,1 \\
\hline $65-70$ & & 54 & 5 & 9,3 \\
\hline $70-75$ & 3 & 45 & 5 & 11,1 \\
\hline $75-80$ & & 58 & 6 & 10,3 \\
\hline $80-85$ & & 30 & 5 & 16,7 \\
\hline $85-90$ & & 27 & 3 & 11,1 \\
\hline $90-95$ & & 24 & 3 & 12,5 \\
\hline $95-100$ & 4 & 15 & 4 & 26,7 \\
\hline $100-105$ & & 4 & 3 & 75 \\
\hline Total & & 1332 & 143 & 10,73 \\
\hline
\end{tabular}

descritas por Babot (2003, 2006, 2007, 2009). El método experimental realizado por Babot (2007) permite observar ciertas modificaciones sufridas por los granos de almidón en diferentes modos de procesamiento: la molienda presenta una alta intensidad de alteraciones del hilo, fisuras, fracturas, relieve deprimido, baja visibilidad, desagregación, alteraciones de la birrefringencia, alteraciones de cruz de extinción y en los rangos de tamaños. El procesamiento de tostado muestra gran recurrencia en las alteraciones del hilo, y en menor medida relieves deprimidos, baja visibilidad, gelatinización, emplastos y alteraciones de la cruz de extinción. Por su parte, la aplicación de calor o calcinado remite a una gran intensidad de gelatinización de los granos de almidón, formación de emplastos y alteraciones de la cruz de extinción. En el caso de la deshidratación, serían menos visibles sus evidencias, debido a que presenta una intensidad intermedia de pérdida en la visibilidad de lamella, y en un grado menos recurrente presenta alteraciones del hilo, fisuras, relieve deprimido, baja visibilidad y alteraciones tanto de birrefringencia como de cruz de extinción. Cabe destacar que la intensidad de estos daños en cada modo de procesamiento corresponden aún a una observación altamente cualitativa de los rasgos, ya que no se ha desarrollado hasta ahora un método estandarizado para medir cuantitativamente la intensidad de cada daño.

Por otra parte, el patrón de daño específico de la elaboración de bebidas fermentadas se adscribió a los siguientes tipos de daños descritos en la literatura: perforación y daño en bordes de los granos de almidón (Babot 2003, 2006; Juan-Tresserras 2000; Quiroz et al. 2012; Wang et al. 2016) superficie rugosa o de surcos y estrías (Arriaza et al. 2015; Henry et al. 2009; Vinton et al. 2009) y gelatinización, la cual se ha reconocido como característica de la aplicación de calor a granos de almidón (Babot 2003, 2007) y se ha documentado como un daño reconocible en los granos de almidón que han sido utilizados para la elaboración de bebidas fermentadas (Wang et al. 2016), lo cual en el caso de la chicha de maíz es esperable debido a la fase de hervido previa a la fermentación (Pardo y Pizarro 2005). Por lo tanto, los daños en granos de almidón arqueológicos se consideraron afines al procesamiento de bebidas fermentadas cuando reunieron mínimamente tres de las características mencionadas anteriormente (perforación, daño en bordes, superficie rugosa o en surcos y gelatinización).

\section{Resultados}

\section{El conjunto recuperado de microrrestos vegetales}

Los microrrestos vegetales recuperados de fragmentería cerámica sumaron 272 elementos. 
De los 143 fragmentos cerámicos muestreados el $64 \%$ presentó algún tipo de microrresto vegetal. Las evidencias vegetales más recurrentes fueron los granos o emplastos de almidón, con un índice de ubicuidad de 1,4 y presentes en 73 fragmentos cerámicos, seguidos por los silicofitolitos, cuyo índice de ubicuidad fue 0,4 y se distribuyeron en 35 fragmentos cerámicos.

Las cuatro muestras de control analizadas presentaron particularidades diferentes de las muestras provenientes de cerámica. De ellas se recuperó 53 microrrestos vegetales, en su mayoría correspondientes a silicofitolitos de la familia Poaceae (morfotipos elongado, buliforme, rondel e irregulares con múltiples fracturas) (Figura 3, Tabla 3). Los granos de almidón recuperados en estas muestras de control fueron solo dos individuos no identificados taxonómicamente debido a su morfología redundante, solo uno de estos granos de almidón posee daños, correspondientes a fracturas. La información de estas muestras permite descartar que agentes naturales sean los responsables de los daños registrados en los granos de almidón adheridos a la fragmentería cerámica, ya que la cantidad de almidones recuperados del sedimento de control fue exigua y presentaron únicamente fracturas en un caso.

\section{Familias y especies de plantas identificadas en los fragmentos cerámicos}

Los granos de almidón recuperados presentaron afinidad taxonómica con cinco especies: fruto de Aristotelia chilensis (Mol.) Stuntz (maqui), granos de Zea mays L. (maíz), hoja de Cestrum parqui L'Herit (palqui), fruto de Fragaria chiloensis (L.) Duchesne (frutilla silvestre) y grano de Phaseolus vulgaris L. (poroto) (Figura 4). Además, pese a la baja concentración de otras evidencias, el conjunto de silicofitolitos constató la presencia de la familia Poaceae (células largas y buliformes) y de la subfamilia Pooideae (rondel).

En cuanto a la asociación temporal, la mayor variedad de especies se concentró en los niveles de ocupación datados alrededor del 1300 d.C. (maíz, frutilla silvestre, maqui y palqui), mientras en el estrato correspondiente a 1000 d.C., solo se identificó granos de almidón afines a Phaseolus vulgaris L. (poroto). Estos últimos presentaron tamaños más pequeños que el promedio de esta especie (9x14 $\mu \mathrm{m}$ y $7 \mathrm{x} 11 \mu \mathrm{m})$, sin embargo, estas medidas están de igual modo dentro de los rangos de tamaño reconocidos para esta herbácea (Babot et al. 2007).

\section{Especies y sus modos de procesamiento}

El 64\% del almidón mostró algún tipo de daño: agrandamiento de hilo (24\%), daño en los bordes (16\%), gelatinización $(15,6 \%)$, pérdida de birrefringencia $(15,6 \%)$, fisuras $(8 \%)$, perforaciones $(6 \%)$, fracturas $(2,8 \%)$ y textura rugosa $(11,2 \%)$. De los 119 almidones con alteraciones el 23,3\% tuvo al menos tres de los siguientes daños: perforaciones, gelatinización, daño en los bordes, texturarugosa(Figura 5). El resto del almidón con alteraciones permitió inferir algunos posibles modos de procesamiento: aplicación de calor (presente en cinco fragmentos cerámicos), tostado (presente en ocho fragmentos cerámicos), deshidratación (presente
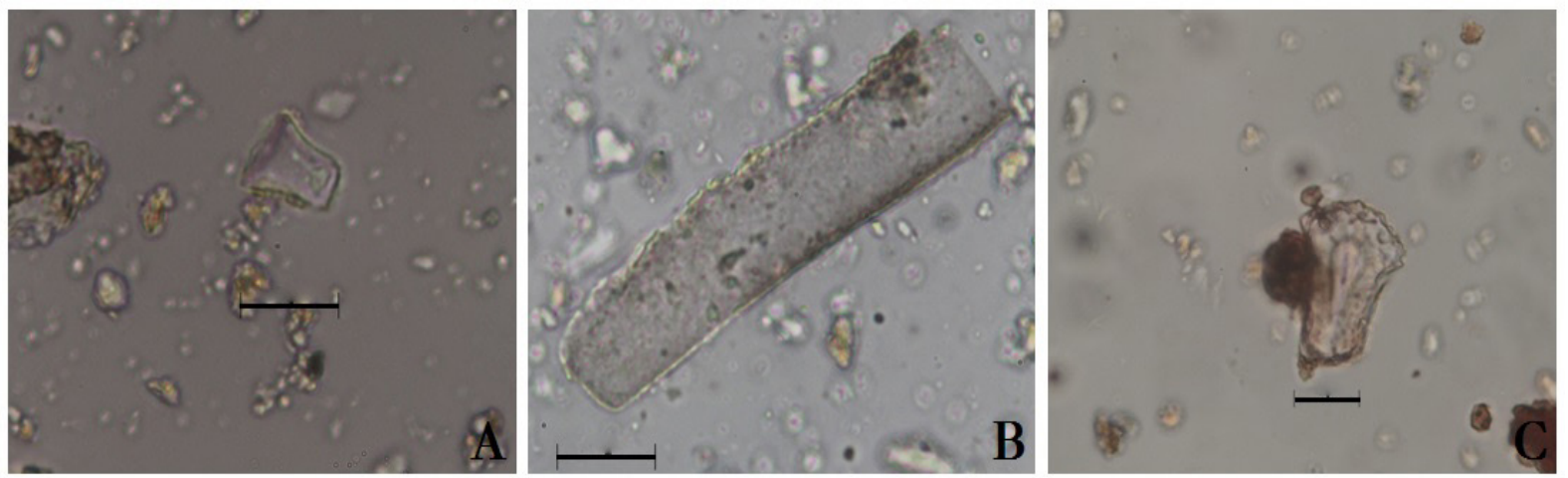

Figura 3. Morfotipos de silicofitolitos presentes en las muestras de control, sitio P5-1. A. Rondel, luz transmitida. B. Elongado-psilado, luz transmitida. C. Buliforme, luz transmitida. Escala $20 \mu \mathrm{m}$.

Morphotypes of silicophytoliths present in the control samples, P5-1 site. A. Rondell, transmitted light. B. Elongate-psilate, transmitted light. C.

Bulliform, transmitted light. Bar-scale $20 \mu \mathrm{m}$. 
Tabla 3. Frecuencia de microrrestos vegetales en las muestras de control de cada capa estratigráfica. Frequency of vegetable micro-remains in the control samples from each stratigraphic layer.

\begin{tabular}{ccccccc}
\hline Capa & Total microrrestos & Silicofitolitos & Tricomas & Grano de almidón & Calcifitolitos & Tejidos \\
\hline 1 & 8 & 7 & 1 & 0 & 0 & 0 \\
2 & 20 & 13 & 0 & 1 & 0 & 5 \\
3 & 8 & 7 & 0 & 0 & 1 & 0 \\
4 & 20 & 15 & 0 & 1 & 0 & 4 \\
\hline
\end{tabular}
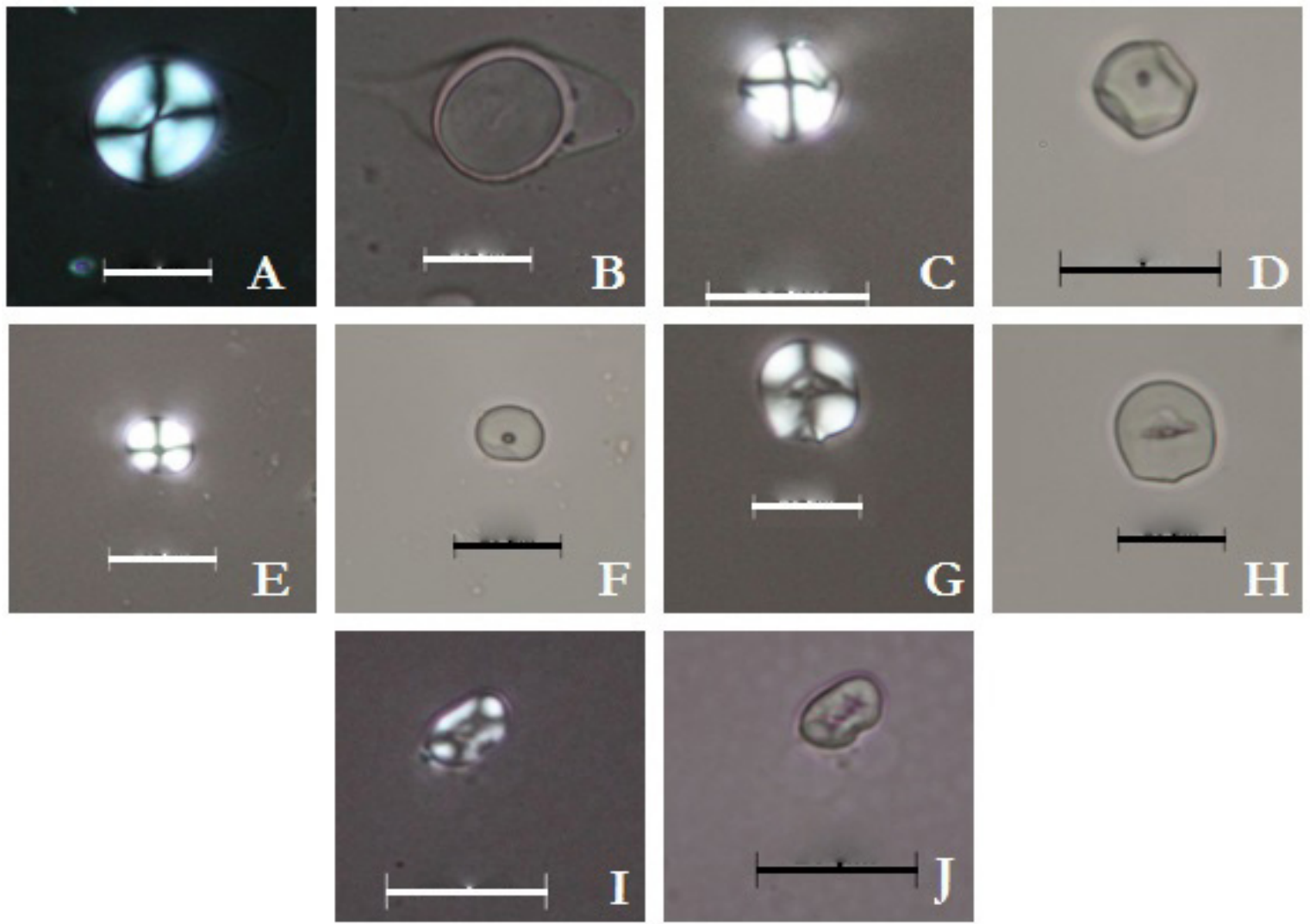

Figura 4. Granos de almidón arqueológicos diagnósticos. A. Almidón de Aristotelia chilensis, luz polarizada. B. Almidón de A. chilensis, luz transmitida. C. Amidón de Zea mays, luz polarizada. D. Almidón de Z. mays, luz transmitida. E. Almidón de Cestrum parqui, luz polarizada. F. Almidón de $C$. parqui, luz transmitida. G. Almidón de Fragaria chiloensis, luz polarizada. H. Almidón de $F$. chiloensis, luz transmitida. I. Almidón de Phaseolus vulgaris, luz polarizada. J. Almidón de P. vulgaris, luz transmitida. Escala $20 \mu \mathrm{m}$.

Diagnostic archeological starch grains. A. Aristotelia chilensis stach grain, polarized light. B. A. chilensis starch grain, transmitted light. C. Zea mays starch grain, polarized light. D. Z. mays starch grain, transmitted light. E. Cestrum parqui starch grain, polarized light. F. C. parqui L'Herit starch grain, transmitted light. G. Fragaria chiloensis starch grain, polarized light. H. F. chiloensis starch grain, transmitted light. I. Phaseolus vulgaris starch grain, polarized light. J. P. vulgaris starch grain, transmitted light. Bar-scale $20 \mu m$.

en cuatro fragmentos cerámicos) y molienda (presente en cuatro fragmentos cerámicos).

Respecto a las especies vinculadas a fermentación, solo Zea mays L y Aristotelia chilensis (Mol.) Stuntz se asociaron a otros granos de almidón - no identificables taxonómicamente debido a sus daños- los cuales mostraban signos de fermentación. Sin embargo, la información contextual del fragmento cerámico IM5-213.6 indica que las tres especies recuperadas (frutilla silvestre, palqui y maíz) estaban contenidas en la superficie interior de un fragmento de jarro, por lo tanto nos lleva a plantear que estos vegetales se estarían utilizando para la elaboración de brebajes. Adicionalmente, se observaron otros posibles modos de procesamiento relacionados con granos de almidón identificados taxonómicamente: posible deshidratación en un caso de granos de almidón de maíz, posible molienda y aplicación de 

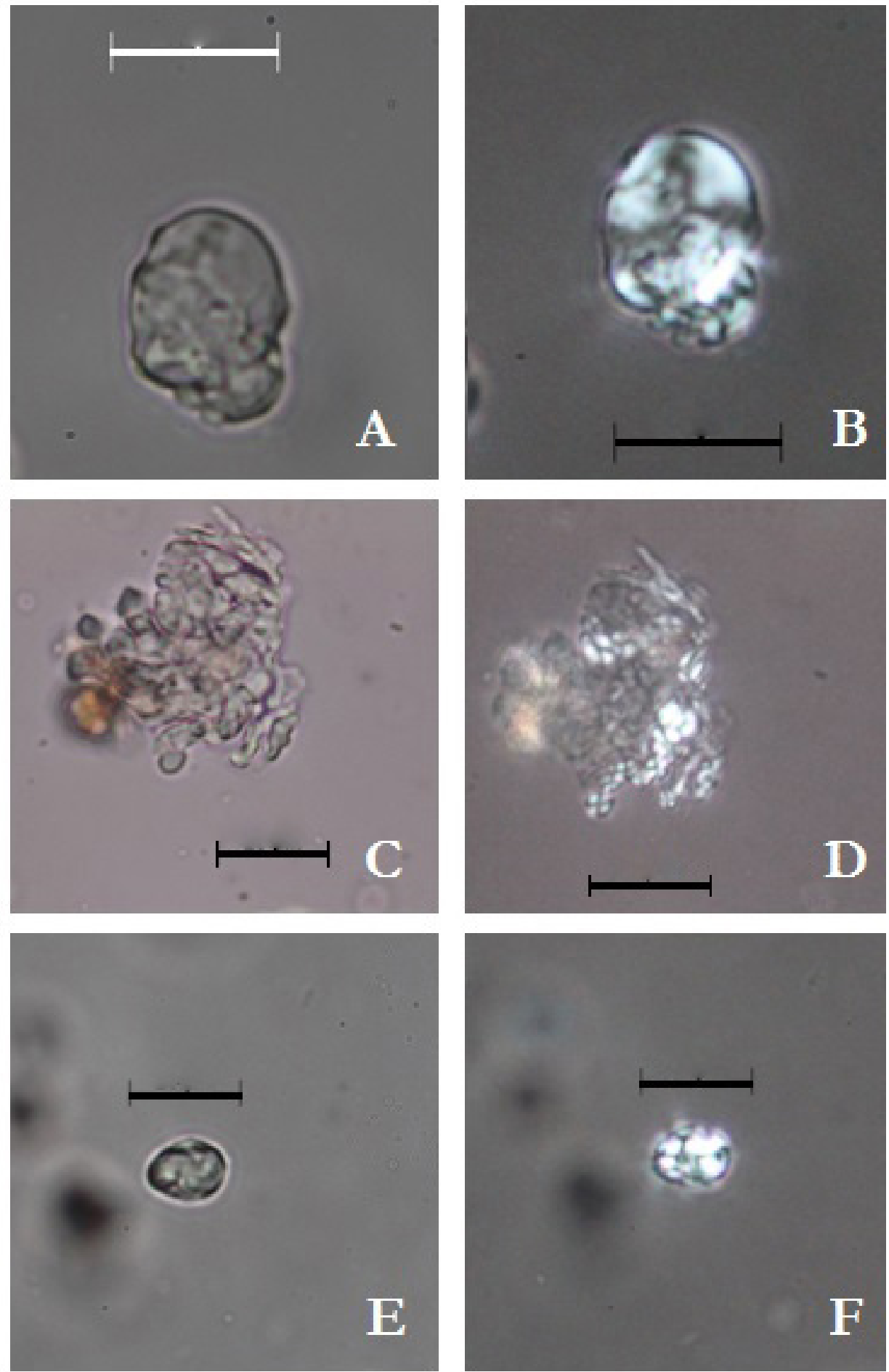

Figura 5. Granos de almidón arqueológicos con daños afines a fermentación. A. Grano de almidón compuesto, luz transmitida. B. Grano de almidón compuesto, luz polarizada. C. Emplasto de almidón, luz transmitida. D. Emplasto de almidón, luz polarizada. E. Grano de almidón simple, luz transmitida. F. Grano de almidón simple, luz polarizada. Escala $20 \mu \mathrm{m}$

Archaeological starch grains with fermentation-related damage. A. Compound starch grain, transmitted light. B. Compound starch grain, polarized light. C. Clump of starch grain, transmitted light. D. Clump of starch grain, polarized light. E. Simple starch grain, transmitted light. F. Simple starch grain, polarized light. Bar-scale $20 \mu \mathrm{m}$. 
calor asociados a frutilla silvestre, posible molienda de granos de almidón asociados con un almidón de maqui, aplicación de calor en un grano de almidón afín a Phaseolus vulgaris (cf).

\section{La cerámica y su relación con la fermentación}

Todas las categorías morfofuncionales cerámicas tuvieron representación de al menos un fragmento con presencia de almidones fermentados. Sin embargo, la categoría "jarros" fue la que concentró una mayor cantidad (24\%) (Tabla 4). Por su parte, los fragmentos decorados tuvieron una baja representatividad dentro de la muestra estudiada (ocho fragmentos rojo engobados), sin embargo, en cinco de ellos se registraron almidones con daños vinculados a fermentación. Las categorías morfofuncionales de estos fragmentos correspondieron a jarros (cuatro fragmentos) y ollas (un fragmento) (Tabla 5).

Los fragmentos asociados a evidencias vegetales fermentadas se ubicaron en toda la secuencia temporal fechada para el sitio (1000-1300 d.C.). Sin embargo, si bien los niveles correspondientes al 1300 d.C. mostraron mayor número de fragmentos cerámicos que dieron cuenta de esta modalidad de procesamiento (14 fragmentos), versus una escasa cantidad de estas evidencias alrededor del 1000 d.C. (un fragmento), es importante recordar que el estrato correspondiente a esta última fecha posee una cantidad mucho menor de muestras cerámicas, por lo que no es posible una comparación entre períodos a partir de estos datos.

Tabla 4. Resumen de la relación entre categorías morfofuncionales y la presencia de fragmentos cerámicos asociados a estructuras de almidón con un patrón de daño sugerente de fermentación.

Summary of the relation between morphofunctional categories and the presence of pottery fragments associated with starch structures with a damage pattern suggestive of fermentation.

\begin{tabular}{cccc}
\hline $\begin{array}{c}\text { Categoría } \\
\text { morfofuncional }\end{array}$ & $\begin{array}{c}\text { Frecuencia de } \\
\text { fragmentos } \\
\text { cerámicos con } \\
\text { presencia de } \\
\text { fermentación }\end{array}$ & $\begin{array}{c}\text { Porcentaje de } \\
\text { fragmentos } \\
\text { cerámicos con } \\
\text { presencia de } \\
\text { fermentación }\end{array}$ & $\begin{array}{c}\text { Total de } \\
\text { fragmentos } \\
\text { según } \\
\text { categoría }\end{array}$ \\
\hline $\begin{array}{c}\text { Jarros } \\
\text { escudilla } \\
\text { Cuenco, } \\
\text { escudilla o } \\
\text { jarro } \\
\text { Ollas }\end{array}$ & 1 & 24 & 25 \\
Urnas & 2 & 6,25 & 16 \\
& 7 & 12,5 & 16 \\
Indeterminado & 1 & 15,4 & 69 \\
\hline
\end{tabular}

Los modos de procesamiento inferidos (fermentación, aplicación de calor, tostado, deshidrataciónymolienda)mostraron particularidades de acuerdo a la categoría cerámica de la cual se recuperaron (Tabla 6): todas las categorías morfofuncionales mostraron granos de almidón con fermentación. La categoría morfofuncional que reunió la mayor variedad de modos de procesamiento fueron las ollas. Por otra parte, los fragmentos de jarros mostraron mayor concentración de muestras con presencia de fermentación, aunque no es una modalidad de procesamiento exclusiva para estas piezas. En cuanto a las urnas la única modalidad de procesamiento inferida en esta categoría fue la fermentación (en dos piezas). A pesar de ello, algunos fragmentos de urnas contuvieron almidones con daños indeterminados, granos de almidón íntegros y granos de almidón con patrón de daño enzimático. Finalmente, cuencos o escudillas mostraron casos de fermentación, daños indeterminados, granos de almidón íntegros, tostado y aplicación de calor.

\section{Discusión y Conclusiones}

Este primer acercamiento a los microrrestos vegetales en la cerámica de Isla Mocha, nos ha permitido obtener algunas señales acerca de la elaboración y consumo de bebidas fermentadas en un sitio El Vergel de este territorio. Estas señales están presentes desde el primer período de ocupación del sitio (alrededor del 1000 d.C.), momento que coincide con el inicio de la construcción de los dos montículos o kuel, consignados como monumentos públicos erigidos en la fase "fundacional" de esta isla por los grupos El Vergel (Campbell y Pfeiffer 2016). Posteriormente, las prácticas de elaboración de bebidas fermentadas continúan hasta al menos el 1300 d.C. dentro del sitio P5-1.

Nuestro interés inicial en comprender las modalidades de procesamiento evidentes en los microrrestos de la cerámica del sitio P5-1 radicaba principalmente en verificar el supuesto de que la especie Zea mays L., cumplía un rol sociopolítico asociado a la elaboración de bebidas fermentadas. A partir de nuestros resultados se observa que esta especie efectivamente se habría asociado a la modalidad de procesamiento de fermentación, sin embargo no es exclusiva de ello: las especies maqui y frutilla silvestre se mostraron también relacionadas a este uso. En el caso del maqui, este se encontró directamente asociado a granos de almidón fermentados, mientras que la frutilla silvestre se recuperó del interior de un fragmento de jarro.

En el caso de las especies que se encontraron asociadas a una misma muestra cerámica (Fragaria 
Tabla 5. Resumen de las principales características de fragmentos cerámicos asociados a estructuras de almidón con patrón de daño de fermentación. Summary of main characteristics of pottery fragments associated with starch structures with a damage pattern suggestive of fermentation.

\begin{tabular}{|c|c|c|c|c|c|c|c|c|}
\hline Muestra & $\begin{array}{c}\mathrm{Capa} / \\
\text { (nivel cm) }\end{array}$ & Forma & $\begin{array}{c}\text { Categoría } \\
\text { morfofuncional }\end{array}$ & Decoración & Huellas de uso & Daños presentes & $\begin{array}{l}\text { Modalidad de } \\
\text { procesamiento } \\
\text { inferida }\end{array}$ & $\begin{array}{l}\text { Identificación } \\
\text { taxonómica }\end{array}$ \\
\hline IM5-194.6 & $\begin{array}{c}1 / 3 \\
(15-20)\end{array}$ & Cuerpo & Indeterminado & & & $\begin{array}{l}\text { Gelatinización, daño en } \\
\text { bordes, superficie rugosa }\end{array}$ & $\begin{array}{l}\text { Fermentado, posible } \\
\text { tostado }\end{array}$ & \\
\hline IM5-501.6 & $\begin{array}{c}1 / 3 \\
(15-20)\end{array}$ & Cuerpo & Olla & $\begin{array}{c}\text { Rojo engobado } \\
\text { interior }\end{array}$ & & $\begin{array}{l}\text { Gelatinización, daño en } \\
\text { bordes, superficie rugosa }\end{array}$ & Fermentado & \\
\hline IM5-198.6 & $\begin{array}{c}1 / 3 \\
(15-20)\end{array}$ & Cuerpo & Olla & & & $\begin{array}{l}\text { Perforaciones, daño en } \\
\text { bordes, superficie rugosa }\end{array}$ & Fermentado & \\
\hline IM5-203.6 & $\begin{array}{c}1 / 4 \\
(20-25)\end{array}$ & Cuerpo & Jarro & $\begin{array}{l}\text { Rojo engobado } \\
\text { /pintura roja } \\
\text { exterior }\end{array}$ & & $\begin{array}{c}\text { Perforaciones, gelatinización, } \\
\text { daño en bordes, superficie } \\
\text { rugosa }\end{array}$ & Fermentado & \\
\hline IM5-205.6 & $\begin{array}{c}1 / 4 \\
(20-25)\end{array}$ & Cuerpo & Olla & & $\begin{array}{c}\text { Ahumado } \\
\text { interior }\end{array}$ & $\begin{array}{l}\text { Perforaciones, gelatinización, } \\
\text { daño en bordes, superficie } \\
\text { rugosa }\end{array}$ & Fermentado & Maíz (n=2) \\
\hline IM5-210.6 & $\begin{array}{c}1 / 4 \\
(20-25)\end{array}$ & Cuerpo & Urna & & & $\begin{array}{c}\text { Perforaciones, gelatinización, } \\
\text { daño en bordes, superficie } \\
\text { rugosa }\end{array}$ & Fermentado & \\
\hline IM5-214.6 & $\begin{array}{c}1 / 5 \\
(25-30)\end{array}$ & Cuerpo & Cuenco o escudilla & & Hollín exterior & $\begin{array}{l}\text { Perforaciones, daño en } \\
\text { bordes, superficie rugosa }\end{array}$ & Fermentado & \\
\hline IM5-220.6 & $\begin{array}{c}1 / 5 \\
(25-30)\end{array}$ & Cuerpo & Olla & & & $\begin{array}{l}\text { Perforaciones, daño en } \\
\text { bordes, superficie rugosa }\end{array}$ & Fermentado & \\
\hline IM5-222.6 & $\begin{array}{c}1 / 5 \\
(25-30)\end{array}$ & Cuerpo & Probable olla & & & $\begin{array}{l}\text { Gelatinización, daño en } \\
\text { bordes, superficie rugosa }\end{array}$ & Fermentado & \\
\hline IM5-62.6 & $\begin{array}{c}2 / 6 \\
(30-35)\end{array}$ & Cuerpo & Olla & & & $\begin{array}{l}\text { Gelatinización, daño en } \\
\text { bordes, superficie rugosa }\end{array}$ & Fermentado & \\
\hline IM5.57.6 & $\begin{array}{c}2 / 8 \\
(40-45)\end{array}$ & Cuerpo & $\begin{array}{l}\text { Cuenco, escudilla } \\
\text { o jarro }\end{array}$ & & & $\begin{array}{l}\text { Perforaciones, daño en } \\
\text { bordes, superficie rugosa }\end{array}$ & Fermentado & \\
\hline IM5-249.6 & $\begin{array}{c}3 / 11 \\
(55-60)\end{array}$ & Cuerpo & Jarro & $\begin{array}{l}\text { Rojo engobado } \\
\text { exterior }\end{array}$ & & $\begin{array}{l}\text { Gelatinización, daño en } \\
\text { bordes, superficie rugosa }\end{array}$ & Fermentado & \\
\hline IM5-259.6 & $\begin{array}{c}3 / 12 \\
(60-65)\end{array}$ & Cuerpo & $\begin{array}{l}\text { Cuenco, escudilla } \\
\text { o jarro }\end{array}$ & & & $\begin{array}{l}\text { Gelatinización, daño en } \\
\text { bordes, superficie rugosa }\end{array}$ & Fermentado & \\
\hline IM5-262.6 & $\begin{array}{c}3 / 12 \\
(60-65)\end{array}$ & Cuerpo & Jarro & & & $\begin{array}{l}\text { Perforaciones, daño en } \\
\text { bordes, superficie rugosa }\end{array}$ & Fermentado & \\
\hline IM5-273.6 & $\begin{array}{c}3 / 15 \\
(75-80)\end{array}$ & Cuerpo & Jarro & $\begin{array}{l}\text { Rojo engobado } \\
\text { exterior }\end{array}$ & & $\begin{array}{l}\text { Gelatinización, } \\
\text { perforaciones, superficie } \\
\text { rugosa }\end{array}$ & Fermentado & Maqui $(\mathrm{n}=1)$ \\
\hline IM5-274.6 & $\begin{array}{c}3 / 15 \\
(75-80)\end{array}$ & Cuerpo & Jarro & & & $\begin{array}{l}\text { Gelatinización, daño en } \\
\text { bordes, superficie rugosa }\end{array}$ & Fermentado & \\
\hline IM5-276.6 & $\begin{array}{c}3 / 15 \\
(75-80)\end{array}$ & Cuerpo & Olla & & & $\begin{array}{l}\text { Gelatinización, daño en } \\
\text { bordes, superficie rugosa }\end{array}$ & Fermentado & \\
\hline IM5-279.6 & $\begin{array}{c}3 / 16 \\
(80-85)\end{array}$ & Cuerpo & Jarro & $\begin{array}{l}\text { Rojo engobado } \\
\text { exterior }\end{array}$ & & $\begin{array}{l}\text { Gelatinización, daño en } \\
\text { bordes, superficie rugosa }\end{array}$ & Fermentado & \\
\hline IM5-42.6 & $\begin{array}{c}4 / 19 \\
(95-100)\end{array}$ & Cuerpo & Urna & & & $\begin{array}{l}\text { Gelatinización, } \\
\text { perforaciones, daño en } \\
\text { bordes }\end{array}$ & Fermentado & \\
\hline
\end{tabular}

Tabla 6. Daños y Modalidades de procesamiento inferidas según categoría morfofuncional asignada a los fragmentos cerámicos de la muestra.

Damage and modes of processing inferred from assigned morphofunctional category to pottery fragments in the sample.

\begin{tabular}{ccccc}
\hline Categoría morfofuncional & Jarro & $\begin{array}{c}\text { Cuenco o } \\
\text { escudilla }\end{array}$ & Olla & Urna \\
\hline $\begin{array}{c}\text { Cantidad Total de } \\
\text { Fragmentos } \\
\text { modos de } \\
\text { procesamiento inferidos }\end{array}$ & 25 & 16 & 69 & 13 \\
Fermentación & 6 & 1 & 7 & 2 \\
Daños indeterminados & 4 & 3 & 6 & 3 \\
Almidones íntegros & & 1 & 12 & 1 \\
Tostado & & 1 & 5 & \\
Aplicación de calor & & 1 & 4 & \\
Molienda & & & 4 & \\
Deshidratación & & & 3 & \\
Ataque enzimático & & & & \\
\hline
\end{tabular}

chiloensis (L.) Duchesne y Zea mays L.), se debe recordar que no es posible diferenciar mediante este análisis si cada una fue preparada como una bebida por separado, quedando luego los residuos acumulados en la vasija mediante usos sucesivos, o si, por el contrario, habrían sido mezcladas de forma deliberada en las preparaciones. Esta última propuesta no puede descartarse, ya que obedecería a gustos culinarios de estos grupos, los cuales son imposibles de afirmar a través del registro arqueológico.

Adicionalmente, nuestros resultados permitieron identificar otras especies no relacionadas con las bebidas fermentadas, pero que entregan importantes antecedentes para la zona de estudio: un grano de almidón de Cestrum parqui L'Herit (palqui) identificado sin daños en un fragmento de jarro. Esta especie endémica de la zona no había sido 
recuperada arqueológicamente. Su presencia en un jarro podría mostrar su uso medicinal en el contexto (Mösbach 1999). Además, se corrobora la presencia de Phaseolus vulgaris L. presente desde el primer momento de ocupación del sitio (1000 d.C.). Otros antecedentes de esta especie en la zona de estudio remiten a un carporresto consignado como $P$. vulgaris en el sitio P29-1 de Isla Mocha, fechado en 1049-1384 cal. d.C (Roa 2011; Roa et al. 2014), además de un cotiledón símil a $P$. vulgaris en el mismo sitio P5-1 y dentro del mismo período de ocupación para el cual fueron recuperados nuestros almidones, es decir alrededor del 1000 d.C. (Roa 2016). Por su parte en El Arenal-1 se recuperaron también carporrestos de leguminosa afín a Phaseolus sp. (Silva 2010b). Estos antecedentes permiten pensar que los grupos El Vergel manejaban la especie P. vulgaris L. ya desde el 1000 d.C. en Isla Mocha.

En cuanto a la información provista por el registro cerámico, los resultados sugieren que los pasos de "molienda, hervido y fermentación", necesarios para la elaboración de estas bebidas (Coña 2010 [1930]; Mösbach 1999; Pardo y Pizarro 2005) se dan de forma completa dentro del conjunto de vasijas del sitio, al encontrarse señales de fermentación en todas las categorías morfofuncionales. A partir de esto se propone que los jarros serían la categoría que recibe el producto fermentado final. Por otra parte, las ollas mostraron tanto evidencias de fermentación como otros múltiples modos de procesamiento, entre ellos la molienda y aplicación de calor, lo cual sugiere que en este tipo de contenedores se realizó la preparación de los productos fermentados en una fase intermedia. A pesar de lo anterior, se debe recordar que esta propuesta no excluye el uso de estos contenedores para la elaboración de otro tipo de alimentos además de las mencionadas bebidas fermentadas. En cuanto a las señales de fermentación en urnas si bien están presentes, son aún exiguas como para realizar aún algún tipo de propuesta concreta. Finalmente, cuencos o escudillas tuvieron solo un caso de granos de almidón fermentados, sin embargo, este dato indica que no debe descartarse a priori el uso de enseres no restringidos para contener líquidos en estos contextos.

La reconstrucción -aunque fragmentaria- de esta secuencia operativa, lleva a reflexionar sobre la conexión del espacio doméstico con la economía pública que implican la producción y servicio de estas bebidas (Adán 2014; Boccara 2007; Clarke 2001; Jennings 2004; Pardo y Pizarro 2005). La información etnográfica de tiempos reche-mapuche indica que la preparación era una labor realizada por mujeres dentro del hogar, por lo tanto su producción está ligada a la economía doméstica, mientras que el servicio de la bebida se habría realizado en un momento más público, donde es ofrecida por el hombre a sus invitados, convirtiéndose así en un bien de prestigio envuelto en un contexto de poder y autoridad (Adán 2014; Dietler 2006). En relación a esto, nuestros resultados indican la presencia de categorías morfofuncionales tanto para los momentos de preparación como de servicio dentro del sitio, sugiriendo que esta cultura material proveía de la conexión entre las dimensiones domésticas y públicas en el contexto. El servicio de estas preparaciones es relevante y algunos autores plantean que la cerámica para este fin debió estar especificada, probablemente correspondiendo a vasijas decoradas (Adán 2014). En nuestro caso de estudio solo ocho fragmentos decorados (rojo engobados) ingresaron a nuestra muestra, mostrando cinco de ellos señales de fermentación. Además, cuatro de estos fragmentos correspondían a formas restringidas o jarros, por lo que es muy posible que esta categoría resulte especificada para el servicio. Si bien nuestros datos son aún escasos, sería interesante trabajar sobre esta hipótesis, debido a que la decoración de engobe rojo es la única que se encuentra presente absolutamente en todos los sitios El Vergel de la isla (Palma et al. 2015).

Estas conclusiones plantean un escenario donde aún quedan múltiples preguntas respecto a las implicancias sociales que estas bebidas tuvieron para los grupos El Vergel de Isla Mocha. La realización de un estudio comparado intersitio aportaría datos que ayuden a dilucidar estos aspectos: posible exclusividad de especies utilizadas, diferencias significativas de la vajilla asociada, intensificación de señales de fermentación en algunos sitios por sobre otros, etc. Es una tarea pendiente evaluar si existirían posibles intensificaciones en la producción de estas bebidas entre períodos de ocupación de los sitios de Isla Mocha. Además, continúa pendiente explorar esta temática posterior al 1300 d.C. en los contextos de esta isla.

Finalmente, reconocemos el potencial del análisis de microrrestos vegetales, que posee la fortaleza de acercarnos a los modos de procesamiento de estos recursos en el pasado. Sin embargo, sabemos que esta metodología posee un fuerte componente cualitativo, donde la intensidad de los daños no posee aún una estandarización bien definida, pudiendo mejorarse en el futuro mediante el apoyo de un análisis cuantitativo de los daños presentes en cada patrón. Por otra 
parte, varios de los daños presentes son compartidos por diferentes modos de procesamiento, pudiendo diferenciarse solo en términos de la intensidad y recurrencia del daño, lo cual hace aún más urgente elaborar una escala cuantitativa de intensidad de los daños. Además, las colecciones de referencia son de vital importancia para este tipo de análisis y requieren de un trabajo constante que en nuestra zona de estudio es aún incipiente. Esperamos que el avance en estas metodologías nos permita a fututo reasignar muchos de nuestros resultados que hoy fueron considerados como indeterminados, estableciendo así conclusiones más completas y enriquecedoras para este tipo de temáticas en la prehistoria.
Agradecimientos: A Roberto Campbell, a los Proyectos Fondecyt 3130515, 11150397 y a cada uno de sus participantes. A las arqueobotánicas Luciana Quiroz, Constanza Roa, Claudia Silva, Ximena Albornoz. A las profesoras Fernanda Falabella y Carolina Belmar por su guía y tutoría en la Memoria de la cual se desprende este trabajo. Al Departamento de Geología y la Facultad de Ciencias Sociales de la Universidad de Chile por facilitar el acceso a sus microscopios. A Leslie Benito, Renata Gutiérrez y Gabriela Zúñiga por su colaboración con las imágenes. A los evaluadores anónimos por sus revisiones y comentarios a este trabajo.

\section{Referencias Citadas}

Adán, L. 2014. Los Reche-Mapuche a Través de su Sistema de Asentamiento (S. XV-XVII). Tesis para optar al grado de Doctora en Historia Mención Etnohistoria, Facultad de Filosofía y Humanidades, Universidad de Chile, Santiago.

Albán, M., G. Palma y A. Delgado 2013. Informe de análisis cerámico sitio P5 Isla Mocha, Comuna de Lebu, Provincia de Arauco, VIII Región del Biobío Fondecyt 3130515. Manuscrito en posesión de los autores.

Alvarado, M. 1997a. La tradición de los grandes cántaros: reflexiones para una estética del "envase". Aisthesis 30:105124.

Alvarado, M. 1997b. Proposiciones para un análisis y sistematización del dominio cerámico mapuche: una reflexión desde la estética. Actas del XIV Congreso Nacional de Arqueología Chilena, pp. 385-403. Copiapó.

Albornoz, X. 2014. Plantas Sagradas en Grupos del Norte Semiárido, un Contexto Diaguita-Inca. Memoria para optar al título de arqueóloga, Facultad de Estudios del Patrimonio Cultural, Universidad Internacional SEK, Santiago.

Aldunate, C. 2005. Comentario: Una reevaluación del complejo cultural el Vergel. Actas del XVI Congreso de Arqueología Chilena, pp. 331-336. Editorial Escaparate, Copiapó.

Arriaza, B., J.P. Ogalde, J. Chacama, V. Standen, L. Huamán y F. Villanueva 2015. Estudio de almidones en queros de madera del norte de Chile relacionados con el consumo de chicha durante el Horizonte Inca. Estudios Atacameños 50:59-84.

Arthur, J. 2003. Brewing beer: status, wealth and ceramic use alteration among the Gamo of south-western Ethiopia. World Archaeology 34:516-528.

Babot, M.P. 2003. Starch grain damage as an indicator of food processing. En Phytolith and Starch Research in the Australian-Pacific-Asian Regions: The State of the Art, editado por D. Hart y L. Wallis, pp. 69-81. Pandamus Books for the Centre for Archaeological Research, Canberra.

Babot, M.P. 2006. Box 4.4: Damage on starch from processing Andean food plants. En Ancient Starch Research, editado por R. Torrence y H. Barton, pp. 66-67. Left Coast Press, California.

Babot, M.P. 2007. Granos de almidón en contextos arqueológicos: posibilidades y perspectivas a partir de casos del noroeste argentino. En Paleoetnobotánica del Cono Sur: Estudios de Casos y Propuestas Metodológicas, editado por B. Marconetto, N. Oliszewski y M. P. Babot, pp. 95-125. Ferreyra Editor, Córdoba.

Babot, M. P. 2009. La cocina, el taller y el ritual: explorando las trayectorias del procesamiento vegetal en el noroeste argentino. Darwiniana 1:7-30.

Babot, M. P., S. Hocsman, R. Piccón y M. Haros 2012. Recetarios prehispánicos y tradiciones culinarias. Casos de la Puna. En Las Manos en la Masa Arqueologías, Antropologías e Historias de la Alimentación en Suramérica, editado por M.P. Babot, M. Marschoff y F. Pazzarelli, pp. 235-269. Universidad Nacional de Córdoba. Facultad de Filosofía y Humanidades. Museo de Antropología UNC - Instituto Superior de Estudios Sociales UNT, Córdoba.

Babot, M.P., N. Oliszewski y A. Grau 2007. Análisis de caracteres macroscópicos y microscópicos de Phaseolus vulgaris (Fabaceae, Faboideae) silvestres y cultivados del noroeste argentino: una aplicación en arqueobotánica. Darwiniana 45:149-162.

Belmar, C. 2017. Explotación de Recursos Vegetales entre Grupos Cazadores Recolectores. Una Aproximación desde los Microfósiles. Cueva Baño Nuevo 1 Aisén, Chile. Tesis para optar al grado de Doctor en Arqueología, Facultad de Ciencias Sociales, Universidad Nacional del Centro de la Provincia de Buenos Aires, Buenos Aires.

Boccara, G. 2007. Los Vencedores, Historia del Pueblo Mapuche en la Época Colonial. Instituto de Investigaciones Arqueológicas y Museo R. P. Gustavo Le Paige S.J. Universidad Católica del Norte, San Pedro de Atacama.

Bray, T. 2009. The role of Chicha in Inca state expansion: A distributional study of Inca Aríbalos. En Drink, Power, and Society in the Andes, editado por J. Jennings y B. Bowser, pp. 108-132. University Press of Florida, Boca Raton. 
Campbell, R. 2011. Socioeconomic Differentation, Leadership and Residential Patterning at an Araucanian Chiefly Center (Isla Mocha, AD 1000-1700). Tesis para optar al grado de Doctor en Filosofía, Departamento de Filosofía, University of Pittsburgh, Pittsburgh.

Campbell, R. 2013. Informe de avance año 1 (2012-2013) Proyecto FONDECYT 3130515. Manuscrito en posesión del autor.

Campbell, R. y M. Pfeiffer 2016. Early public architecture in southern Chile. Archaeological and pedological results from the Mocha island mounds and platform complex. Manuscrito en posesión de los autores.

Clarke, M. 2001. Aka feasting: an ethnoarchaeological perspective. En Feasts: Archaeological and Ethnographic Perspectives on Food, Politics, and Power, editado por M. Dietler y B. Hayden, pp.144-167. Smithsonian Institution, Washington D.C.

Coña, P. 2010 [1930]. Lonco Pascual Coña. Testimonio de un Cacique Mapuche. Editorial Pehuén, Santiago.

Dietler, M. 2001. Theorizing the feast: rituals of consumption, commensal politics, and power in African contexts. En Feasts: Archaeological and Ethnographic Perspectives on Food, Politics, and Power, editado por M. Dietler y B. Hayden, pp. 65-114. Smithsonian Institution, Washington D.C.

Dietler, M. 2006. Alcohol: anthropological/archaeological perspectives. Annual Review of Anthropology 35:229-249.

Dietler, M. y B. Hayden (eds.) 2001. Feasts: Archaeological and Ethnographic Perspectives on Food. Politics, and Power. Smithsonian Institution, Washington D.C.

Dietler, M e I. Herbich 2006. Liquid material culture: following the flow of beer among the Luo of Kenya. En Grundlegungen. Beiträge zur Europäischen und Afrikanischen Archäologie für Manfred K.H. Eggert, editado por H. Wotzka, pp. 395-408. Tübingen, Francke Verlag.

Dillehay, T. 2007. Monuments, Empires and Resistance. The Araucanian Polity and Ritual Narratives. Cambridge University Press, Cambridge.

Dillehay, T. y J. Saavedra 2010. Los Valles de Purén-Lumaco y Liucura, Chile. Arqueología e Historia Cultural. Vanderbilt University Publications in Anthropology 52, Nashville.

Esau, K. 1976. Anatomía Vegetal. Editorial Omega, Barcelona.

Godoy-Aguirre, C. 2014. Construcción de una colección de referencia de microrrestos vegetales para el estudio de los grupos El Vergel en Isla Mocha (1.000- 1550 d.C.). Informe de práctica profesional, Facultad de Ciencias Sociales, Universidad de Chile, Santiago.

Hayashida, F. 2008. Ancient beer and modern brewers: Ethnoarchaeological observations of chicha production in two regions of the North Coast of Peru. Journal of Anthropological Archaeology 27:161-174.

Henry, A., H. Hudson y D. Piperno 2009. Changes in starch grain morphologies from cooking. Journal of Archaeological Science 36:915-922.

ICSN The International Code for Starch Nomenclature 2011. ICSN Farm. http://fossilfarm.org/ICSN/Code.html, (07 marzo 2016).

IJzerman, J.W. 1926 [1602]. Beschryvinghe Vande Voyagie om den Geheelen Werelt Cloot Ghedaen door Olivier van Noort van Vtrecht. Martinus Nijhoff, 's-Gravenhage.

Ikehara, H., J.F. Paipay y K. Shibata 2013. Feasting with Zea mays in the middle and late formative north coast of Peru. Latin American Antiquity 24:217-231.
Iriarte, J. 2014. Phytolith analysis of sites LU-69 and PU-165. En The Teleoscopic Polity. Andean Patriarchy and Materiality, editado por T. Dillehay, pp. 221- 233. Springer, Vanderbilt University, Nashville.

Jennings, J. 2004. La Chichera y El Patrón: chicha and the energetics of feasting in the prehistoric Andes. Archeological Papers of the American Anthropological Association 14:241-259.

Jennings, J. y B. Bowser (eds.) 2009. Drink, Power, and Society in the Andes. University Press of Florida, Boca Raton.

Juan-Tresserras, J. 2000. La cerveza: un producto de consumo básico entre las comunidades ibéricas del NE peninsular. SAGVNTVM Papeles del Laboratorio de Arqueología de Valencia Extra 3:139-145.

Korstanje, M.A y M.P. Babot 2007.A microfossil characterization from South Andean economic plants. En Plants, People and Places: Recent Studies in Phytholithic Analysis, editado por M. Madela y D. Zurro, pp. 41-72. Oxbow Books, Cambridge.

Logan, A., C. Hastorf y D. Pearsall 2012. "Let's drink together": Early ceremonial use of maize in the Titicaca basin. Latin American Antiquity 23:235-258.

Loy, T. 1994. Methods in the analysis of starch residues on prehistoric stone tools. En Tropical Archaeobotany: Applications and New Development, editado por J.Hather, pp. 86-114. Routledge, New York.

Loy, T. y R. Fullagar 2006. Box 9.8. Residue Extraction. En Ancient Starch Research, editado por R. Torrence y H. Barton, pp. 197-198. Left Coast Press, California.

Madella, M., A. Alexandre y T. Ball 2005. International code for phytolith nomenclature 1.0. Annals of Botany 96:253-260.

Mösbach, E.W. 1999. Botánica Indígena de Chile. Editorial Andrés Bello, Santiago.

Mulholland, S y G. Rapp 1992. A morphological classification of grass silica-bodies. En Phytolith Systematics, editado por G. Rapp y S. Mulholland, pp. 65-89. Springer US, Nueva York.

Musaubach, G. y M. Berón 2012. Cocinando en ollas en la pampa occidental. Datos desde la etnohistoria, el registro arqueológico y la arqueobotánica. En Las Manos en la Masa Arqueologías, Antropologías e Historias de la Alimentación en Suramérica, editado por M. Babot, M. Marschoff y F. Pazzarelli, pp. 599-620. Universidad Nacional de Córdoba. Facultad de Filosofía y Humanidades. Museo de Antropología UNC - Instituto Superior de Estudios Sociales UNT, Córdoba.

Núñez de Pineda, F. 1863. Cautiverio Feliz, y Razón de las Guerras Dilatadas de Chile (Vol. 3). Imprenta del Ferrocarril, Santiago.

Palma, G. 2013. Inversión de trabajo en la cerámica El Vergel del sitio P-5 de Isla Mocha. Informe de Práctica Profesional, Facultad de Ciencias Sociales, Universidad de Chile, Santiago.

Palma, G., A. Delgado, M. López y M. Albán 2015. Ocupaciones El Vergel y reche-mapuche en Isla Mocha. Una aproximación desde el conjunto cerámico doméstico. Ponencia presentada en el XX Congreso Nacional de Arqueología Chilena, Concepción.

Pazzarelli, F. 2014. "Otros-maíces”: trayectorias y transformaciones culinarias del maíz en Ambato (Catamarca, noroeste Argentino). Revista Española de Antropología Americana 43:329-351.

Pardo, O y J.S. Pizarro 2005. La Chicha en el Chile Precolombino. Editorial Mare Nostrum, Santiago.

Popper, V. 1988. Selecting quantitative measurements in paleoethnobotany. En Current Paleoethnobotany. Analytical 
Methods and Cultural Interpretations of Archaeological Plant Remains, editado por C. Hastorf y V. Popper, pp.53-71. University of Chicago Press, Chicago.

Quiroga, J.D. 1979 [1692]. Memoria de los Sucesos de la Guerra de Chile. Editorial Andrés Bello, Santiago.

Quiroz, L., C. Belmar, M.T. Planella, R. Mera y D. Munita 2012. Estudio de microfósiles de residuos adheridos en pipas cerámicas del sitio Villa JMC-1 Labranza, Región de la Araucanía. Magallania 40:249-261.

Roa, C. 2011. Los recursos vegetales en el registro arqueológico del Período Alfarero Tardío en Isla Mocha. Informe de práctica profesional, Facultad de Ciencias Sociales, Universidad de Chile, Santiago.

Roa, C. 2013. Informe Análisis Carpológico Fondecyt 3130515 Manuscrito en posesión del autor.

Roa, C. 2016. De la Quinua Mapuche a la Frutilla Silvestre. El Aprovechamiento de Recursos Vegetales de Importancia Alimenticia en Isla Mocha (1000-1687 d.C.). Memoria para optar al título de arqueóloga, Facultad de Ciencias Sociales, Universidad de Chile, Santiago.

Roa, C., C. Silva y R. Campbell 2014. El aporte de Isla Mocha al conocimiento sobre el aprovechamiento de plantas con valor alimenticio en el sur de Chile (1000-1700 D.C.). Actas XIX Congreso Nacional de Arqueología Chilena, pp. 549-559. Arica.
Rojas, G. y A. Cardemil 1995. Estudio arqueobotánico en Isla Mocha. Museos 20:16-17.

Samuel, D. 1996. Investigation of ancient Egyptian baking and brewing methods by correlative microscopy. Science 273:488-489.

Sánchez, M., D. Quiroz y M. Massone 2004. Domesticación de plantas y animales en La Araucanía: datos, metodologías y problemas. Chungara Revista de Antropología Chilena 36:365-372.

Silva, C. 2010a. El Complejo El Vergel y su vergel: vegetales domésticos prehispanos en la costa septentrional araucana. Actas XVII del Congreso Nacional de Arqueología Chilena. Tomo II, pp.1279-1289. Valdivia.

Silva, C. 2010b. Informe de análisis carpológico para muestras arqueológicas de isla mocha. Proyecto NSF BCS-0956229: socioeconomic differentiation, leadership, and residential patterning at an Araucanian chiefly center (Isla Mocha, AD 10001700). Manuscrito en posesión del autor.

Silva, C. 2014. Archaeobotanical remains. En The Teleoscopic Polity. Andean Patriarchy and Materiality, editado por T. Dillehay, pp. 221-233. Springer, Vanderbilt University, Nashville.

Vinton, S., L. Perry, K. Reinhard, C. Santoro y L. Teixeira-Santos 2009. Impact of empire expansion on household diet: the Inka in Northern Chile's Atacama Desert. PloS one 4:e8069- e8069.

Wang, J., L. Liu, T. Ball, L. Yu, Y. Li y F. Xing 2016. Revealing a 5,000-y-old beer recipe in China. Proceedings of the National Academy of Sciences 113:6444-6448. 